\title{
A dictionary of Academic English: A further resource for students in higher
}

\author{
education
}

\author{
Stephen Coffey, Dipartimento di Filologia, Letteratura e Linguistica, Università di Pisa \\ (stephen.james.coffey@unipi.it)
}

\begin{abstract}
This article is primarily a description of the Oxford Learner's Dictionary of Academic English (2014), a reference work aimed at higher education students who are studying through the medium of English but who are not native speakers of English. Description includes comparisons with the more general Oxford Advanced Learner's Dictionary, and is preceded by an introduction to the field of 'English for Academic Purposes'.
\end{abstract}

\section{The Oxford Learner's Dictionary of Academic English: Introduction}

The focal point of this article is the Oxford Learner's Dictionary of Academic English (OLDAE) published in 2014 (see References). The main purpose of the article is to describe the dictionary in some detail, especially since it represents a new type of learner's dictionary. OLDAE was designed for a specific user group, described by the dictionary's chief editor as 'non-native-English-speaking students who are studying academic subjects at tertiary level through the medium of English' (Lea 2014: 181). At the time of its publication, it was, as far as I am aware, the only widely available MLD (monolingual learner's dictionary) to focus exclusively on this set of potential users. ${ }^{1}$

OLDAE comes in the form of a print dictionary and a CD-ROM; the main A-Z part of the dictionary is also downloadable as an app. In addition, there are 'teaching resources' on the publisher's website. $^{2}$

This article is divided into seven sections. The first four deal with, respectively: the field of English for Academic Purposes; the compilation and coverage of OLDAE; lexical entries in the print dictionary; the CD-ROM. Thereafter, shorter sections deal with guidance on how to use the dictionary, and 'non-lexical' data in the dictionary. Lastly, there is an evaluative summary, followed by a series of more general points.

\section{English for Academic Purposes}

From the perspective of the language teaching profession, OLDAE constitutes a new resource within the field of English for Academic Purposes (EAP). Overviews of the nature and development of EAP can be found in Hyland and Hamp-Lyons (2002) and Jordan (2002), both of which form part of the first issue of the Journal of English for Academic Purposes. The first of the two articles, written by the journal's editors, includes the following summarizing statement of the purpose of EAP: 'the growth of English as the leading language for the dissemination of academic knowledge has transformed the educational experiences of countless students, who must now gain fluency in the conventions of English language academic discourses to understand their disciplines and to successfully navigate their learning. The response of the language teaching profession to these demands has been the development over the past 25 years of a new field in the teaching of English 
as a Second/Foreign Language in universities and other academic settings: the field of English for Academic Purposes.' (Hyland and Hamp-Lyons, 2002: 1).

EAP is of relevance both to English-speaking and non-English-speaking countries. As it says in the Introduction to OLDAE itself, 'Greater numbers of international students are choosing to pursue their higher education in English-speaking countries. Additionally, universities and colleges around the world are offering courses in a whole range of academic subjects taught through the medium of English.' (p. v).

In terms of linguistic description and language learning/teaching, EAP is concerned with identifying the particular characteristics which allow us to talk in terms of a general (i.e. crossdisciplinary) 'academic English', and with designing appropriate materials, methodology, and syllabuses to help teach this particular area of English usage. Many published materials are now available which deal with academically focussed aspects of each of the traditional 'four skills', as well as with academic vocabulary and areas of grammatical preference. English language exams should also be mentioned in the context of EAP, especially the 'academic reading' and 'academic writing' components of the IELTS exam. ${ }^{3}$

\subsection{Academic vocabulary}

Within EAP, vocabulary studies is the area of most obvious relevance to dictionary writing. There have been various ELT books published which focus on 'academic vocabulary'. An early example is Sim and Laufer-Dvorkin (1984) and a more recent publication is McCarthy and Dell (2008). The Introduction to the latter gives a clear indication of what is normally meant by 'academic vocabulary': 'This book presents and practises the kind of vocabulary that is used in academic speech and writing regardless of which discipline you are concerned with [....] It does not deal with the specialist vocabulary of any particular subject such as medicine or physics.' (McCarthy and Dell 2008: 6).

However, whereas the general concept of 'academic vocabulary', as described above, is easy to comprehend, it is much more difficult to draw up a list of lexical items which indisputably constitute this particular sub-lexicon of English. Indeed, some researchers have questioned the feasibility of creating a general, cross-discipline, academic word list (see Hyland and Tse, 2007, and, a reader's response to this, Eldridge 2008). Certainly, different lists can be drawn up, and the differences between one list and another will depend on various factors, for example: (i) the nature of the corpus/corpora used to 'discover' the vocabulary in question (I take it as axiomatic that corpus data should be used); (ii) the numerical thresholds used for inclusion/exclusion; (iii) which types of linguistic unit are to be included (just words, or phrases as well; and if phrases, whether collocations are to be included); (iv) the exact purpose of drawing up the list.

Various lists of academic vocabulary have been drawn up in the past. Gardner and Davies (p. 306) cite four lists which were compiled in the 1970s, and which were later combined to become what was known as the University Word List (UWL - see Xue and Nation 1984). In relation to the UWL, Nesi (2002: 352) says that, 'Until fairly recently the most widely discussed wordlist for tertiary level students was the University Word List ..'. She also says that '[a]lthough none of the major learners' dictionaries refer to it, the University Word List has been influential as a tool in English for Academic Purposes, serving as a syllabus component, as a yardstick by which to measure students' knowledge of the words they will need for academic study, and as a teaching tool ..' (ibid., p. 352).

The successor to the UWL was Coxhead's Academic Word List (AWL - see Coxhead 2000). ${ }^{4}$ The AWL is a corpus-derived list of word families (570 in all), which comprise a total of 3,110 individual word forms. A word family is defined as 'a stem plus all closely related affixed forms' 
(ibid., p. 218); affixation includes 'all inflections and the most frequent, productive, and regular prefixes and suffixes' (ibid., p. 218). The purpose of the AWL 'was to help teachers of EAP classes to set goals for their students' vocabulary learning' (Coxhead 2011: 357).

Since the compilation of the AWL, a number of other research projects have addressed the question of identifying a core list of vocabulary items relevant to a broad range of academic disciplines. These include: a 'spoken academic wordlist' (Nesi 2002), an 'academic keyword list' (Paquot 2010: 29-63) ${ }^{5}$, an 'academic formulas list' (Simpson-Vlach and Ellis 2010); an 'academic collocation list' (Ackermann and Chen 2013) ${ }^{6}$; and an 'academic vocabulary list' (Gardner and Davies 2014) ${ }^{7}$.

\subsection{EAP and dictionaries}

Non-native speakers of English studying in higher education have always had at their disposal the resources of 'general' MLDs, initially in their pre-corpus versions, and, since the publication of the first COBUILD dictionary (see References), as corpus-based dictionaries. Such learners' dictionaries include not only the standard, alphabetically arranged works, but also those in which entries are arranged in accordance with meaning, and dictionaries devoted to phraseological phenomena.

In recent editions of some MLDs, AWL vocabulary has been specifically labelled (see Coxhead 2011: 359). Also, the Academic Word List was one of the various sources used in the compilation of the Macmillan Collocations Dictionary, even though AWL words themselves are not indicated as such. ${ }^{8}$

There have also been subject-specific dictionaries of potential use to non-native speaker students in higher education, especially those which include simple explanations and example sentences. Such dictionaries are usually designed and marketed for both second-language users and native speakers; examples are Peter Collin Publishing's Dictionary of Government and Politics (1997 [1988]) and the Cambridge Business English Dictionary (2011).

The need for an additional type of dictionary, which focuses specifically on non-subject-specific 'academic English', was voiced by Kosem at the 2008 Euralex conference (Kosem 2008). Twenty years before that, at a previous Euralex conference, Hollósy had also argued in favour of such a dictionary, though relating it more to the needs of non-native-speaker academics and other professionals than students in higher education (see Hollósy 1990).

\section{OLDAE: Purpose, compilation, coverage}

I have focussed above on the notion of academic vocabulary, and this is only natural, since lexical items constitute the primary organizational level of a non-meaning-based dictionary, and the starting point for dictionary consultation. However, the presentation of lexis in OLDAE is, above all, a means to an end, that of writing academic English (OLDAE, p. vi; Lea 2014: 183).

Writing is probably the language skill with which most students in higher education need the most help, both because it is difficult to master and because of the role it has in many study environments. As Ian Bruce writes (2011: 118): 'Central to the language needs of EAP students is competence in academic writing, because of the importance placed on written assessments in academic courses at all levels. Competence in academic writing also relates to the future needs of graduates to communicate within professional or academic communities through written publications'.

The presumed language level of OLDAE's intended users is quite broad, ranging from 'the B1 student on a foundation course, to students at C2 level writing their Masters' dissertations' (Lea 
2014: 182). The level range is thus broader than that of OALD8 and OALD9, which, according to indications on the dictionary covers, are aimed at the range B2-C2.

\subsection{The Oxford Corpus of Academic English}

OLDAE was compiled with reference to a purpose-built, 85-million-word corpus, the Oxford Corpus of Academic English (OCAE). In a description of the corpus contents, Lea distinguishes between texts which represent the type of material which students will be reading, and texts which represent desired student written output (2014: 183). For the former, higher education textbooks were used, mostly aimed at undergraduate level students. With regard to the latter, Lea says that 'high-quality student essays and dissertations' were considered to be the ideal text type, but adds that this option proved to be unfeasible (ibid., p. 183). The alternative used was 'expert academic writing from journals, monographs and handbooks' (ibid., p. 183). The disadvantage with such writing, Lea explains, was that the text was 'of a much higher level than our students would be attempting to write, which made the selection of authentic but user-friendly example sentences rather more challenging' (ibid., p. 183).

With regard to the balance of disciplines in the corpus, the aim was 'to match this approximately to the profile of disciplines being studied by international students at English-medium universities' (ibid., p. 183). The resulting proportions are: the natural sciences (physical sciences and life sciences) $40 \%$, the social sciences $40 \%$, the humanities $20 \%$. The actual disciplines are the following (taken from the publisher's website): biology, biochemistry, business, chemistry, classical studies, computer science, earth science, ecology, economics, education, engineering, geography, health science, history, law, linguistics, literature, mathematics, media and cultural studies, medicine, philosophy, physics, politics, psychology, religion and sociology. The texts comprising the OCAE were all complete texts (apart from indexes, references lists and so forth), and they were published in the period 2000-2012. A full list can be found in the Reference section of the CD-ROM i-Writer. ${ }^{9}$

\subsection{OLDAE: Lexical coverage}

Although OLDAE is concerned with the language of 'academic English', and is considerably smaller, in terms of its headwords, than recent editions of OALD, it nonetheless includes a reasonably broad spectrum of vocabulary. Fig. 3 includes in succession: the 'technical' word cathode, the fairly 'normal' word Catholic, the specialist term cation, the past form of a common verb (caught), and the 'academic-sounding' causal.

Corpus analysis played an important role in deciding which headwords to include in OLDAE, but it was not the only criterion. The procedure adopted is outlined in the Introduction to the dictionary (p. v) and in Lea 2014 (p. 184). Quoting from the latter, 'The headword list was built up organically as the work of compiling the dictionary progressed. We began with a core list, comprised of words from the AWL, after checking them against the corpus. We added to this four word lists of our own, extracted from the four subcorpora of OCAE, as compared with a fiction corpus. As work began on compiling entries for these words, the headword list was rapidly augmented with necessary defining words, complements, collocations, synonyms and opposites of the words in the initial list. Collocations were an especially rich source of additional headwords.' It was also decided that the headword list should include function words that are 'basic to all forms of discourse' (ibid., p. 184). 
Figure 1 is a list of 100 consecutive headwords taken from a randomly selected section of the dictionary. It is difficult to say whether this is 'representative' or not, but at least it should give some sort of idea of the vocabulary presented in OLDAE.

managerial, managing director, mandate (n), mandate (v), mandatory, manifest (v), manifest (adj), manifestation, manipulate, manipulation, manipulative, mankind, man-made, manner, manoeuvre (n), manoeuvre (v), manslaughter, mantle, manual (adj), manual (n), manually, manufacture (n), manufacture (v), manufacturing, manuscript, many, map (n), map (v), mapping, marble, march (v), march (n), margin, marginal, marginalize, marginally, marine, marital, marital status, mark (v), mark (n), marked, markedly, marker, market (n), market (v), marketable, marketer, market forces, marketing, market leader, marketplace, market price, market research, market share, market value, mark up (n.), marriage, married, marry, masculine, masculinity, mask (n), mask (v), mass (n), mass (adj), massive, massively, the mass media, mass spectrometer, master (n), master (v), mastery, match $(v)$, match $(n)$, mate $(n)$, mate $(v)$, material $(n)$, material $(\operatorname{adj})$, materialism, materialize, materially, maternal, maternity, mathematician, mathematics, mating, matrix, matter (n), matter (v), maturation, mature (adj), mature (v), maturity, maximal, maximize, maximum (adj), maximum (n), may, maybe

Figure 1. 100 consecutive headwords in OLDAE

Out of these 100 entries, all but two are also in OALD8, the exceptions being marketer (which is, however, in OALD9), and mass spectrometer. Sixteen items also appear in the Academic Word List; they are (grouped according to their AWL word family) manipulate, manipulation, manipulative | manual (adj, $\mathrm{n}$ ), manually | margin, marginal, marginally | mature (adj, v), maturation, maturity | maximize, maximum (adj, n).

As can be seen in Fig. 1, grammatically distinct homographs (e.g. map as a noun and map as a verb) each have their own entry in OLDAE; this may be contrasted with OALD, where they are usually subsumed under the same headword.

With fairly broad coverage, it is reasonable to suppose that most items in the various academic word lists will also be present in OLDAE. Certainly, this appears to be true of the Academic Vocabulary List. Of the top 500 lemmas in the AVL (Gardner and Davies, 2014: 317-320), I checked every 10th item for coverage in OLDAE, and all were present as headwords. Most items in the Academic Word List also have entries in OLDAE, and are labelled as such. My rough-andready estimate is that AWL words in OLDAE account for over $90 \%$ of the AWL word forms which would qualify as dictionary headwords. ${ }^{10}$

Another way of viewing headword inclusion is to see what is not present. Fig. 2 consists of a list of 100 consecutive headwords in OALD8 (I have ignored derived words); the words indicated in bold type are those which also appear in OLDAE.

Mass, mass, massacre, massage, massage parlour, masseur, masseuse, massif, massive, mass-market, the mass media, mass noun, mass number, mass-produce, mast, mastectomy, master, masterclass, masterful, master key, masterly, mastermind, master of ceremonies, masterpiece, master plan, master's degree, the Master's Tournament, masterstroke, masterwork, mastery, masthead, mastic, masticate, mastiff, mastitis, masturbate, mat, matador, Mata Hari, matatu, match, matchbook, matchbox, matching, matchless, match maker, match play, match point, matchstick, matchstick figure, matchwood, mate, material, materialism, materialist, materialistic, materialize, materiel, maternal, maternity, maternity leave, mateship, matey, math, mathematician, mathematics, maths, Matilda, matinee, matinee idol, mating, matins, matoke, matriarch, matriarchal, matriarchy, matric, matric exemption, matricide, matriculate, matrilineal, 
matrimonial, matrimony, matrix, matron, matronly, matron of honour, matronymic, matt, matted, matter, matter-of-fact, matting, mattock, mattress, maturation, mature, mature student, maturity, matzo

Figure 2. 100 consecutive headwords in OALD8. Items in bold type are also present in OLDAE.

4. OLDAE: Lexical data in the print dictionary

A sample page from OLDAE can be seen in Figure 3. Entry structure and data are quite similar to those in recent editions of OALD, though, as might be expected, there are also some differences. Below, I point out some of these differences, in particular with regard to OALD8 (the latest edition available when OLDAE was published), and by doing so I hope to define more clearly the nature of OLDAE itself. 


\section{cathode}

catering for synagogue events. o sth (NAmE) They were involved in catering synagogue events.

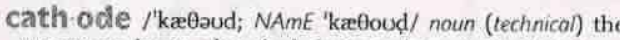
ELECTRODE in an electrical device where REDUCTION happens; the negative electrode in an ELECTROLVTIC cell and the positive electrode in a battery: Hydrogen is formed a the cathode during the electrolysis of seawater. $\approx$ compare ANODE

Cath-olic /'kaelrk/ noun = ROMAN CATHOLIC a Catholi odj. = ROMAN CATHOLIC Cath-olicismi / kə'Odosizom; NAmE

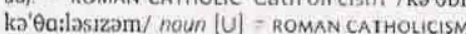

cat.ion / kataron/ noun (chemistry) an ION with a positive electrical CHARGE: When electricity is passed through copper sulfate solution, the copper cations gain electrons and form metallic copper. $\rightarrow$ compare ANION

caught past tense, past part of $\mathrm{CATCH}^{1}$

causal /ko:zl/ adj connected with the relationship between two things, where one causes the other to happen: Research findings have established a causal link between smoking and lung cancer. $\triangle$ DNA damage has draun ample attention in the past because of its causal relationship with cancer. \& The great contribution of Darwin was to realize the causal mechanism for adaptive evolution. was causally related to the prescription of penicillin.

caus.all-ity / ko:'zaloti/ noun [U] 1 (o/so causation) $\sim$ (between A and B) the relationship between sth that happens and the reason for it happening: The assumption of causality between poverty and lack of education may be mistaken, 2 the principle that nothing can happen without a cause: Four distinctive preoccupations can be discerned in quantitative research: measurement, causality generalization and replication.

caus ration / ko:zeljn/ noun [U] 1 the process of one event causing or producing another event: The most com mon risk factors for cancer causation are tobacco use, dietary factors, infective causes and UV light. o of sth Excess cholesterol is a risk factor in causation of heart attacks.

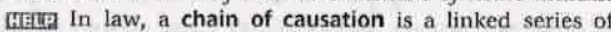
events leading from cause to effect, typically considered when examining a claim for DAMAGES: There are circum stances in which the conduct of the victim may break the chain of causation. $\mathbf{2}=$ CAUSALITY (1)

causa.tive /ko:zatuv/ odj acting as the cause of sth. Smoking is a causative factor for lung cancer.

cause $^{1} / \mathrm{k}$ : :z/verb to make sth happen, especially sth bad or unpleasant: sth If inhaled, the gas can cause damage to the lungs. $\bigcirc \sim$ sth for sb Personality disorder may cause difficulties for elderly patients and their families. $\diamond \sim$ sth to do sth High elevation of mountain ranges causes them to erode rapidly. $\diamond \sim \mathrm{sb}$ sth $\mathrm{He}$ is reluctant to cough as this causes him considerable pain. O language bank at BECAUSE - CAUSE + NOUN damage, harm, injury • problems, difficulties - disruption - confusion - anxiety, concern distress These processes cause significant engineering problems for roads, buildings and other structures.

disease, infection, illness, syndrome, disorder - cancer . death - pain There are several types of infection caused by fungi. | increase + reduction + change • delay + loss Invasive GM plants might cause changes in communities of other plants.

ADVERB + CAUSE usually * often, frequently * commonly, generally + typically + rarely + directly + mainly, largely primarily + partly + thus, thereby $*$ probably + actually $\mathrm{CO}_{2}$ and other greenhouse gases may trap the outgoing thermal radiation from the earth, thereby causing global warming.

\section{ANCWACEBAWK}

Cause and effect

In academic writing, you often need to show a link between two or more actions or events, or link a cause $X$ to an effect $Y$.

- $X$ causes/produces/leads to/brings about/results in $Y$

D $Y$ is caused by/is due to $X$.

- $X$ has/exerts an influence on $Y$

$\rightarrow X$ has an effect/impact on $Y$.

- As a result of $X$.

1.... because..

*.... consequently/therefore..

- There is no scientific evidence that magnetic fields in that range produce harmful effects in humans.

- Higher levels of employment bring about higher rates of capacity utilization.

- Application of the points system has resulted in an increase in the number of qualified professionals.

- The majority of air pollutants are caused by industry or transport.

- Only about half of the permafrost warming is due to an increase in air temperature.

- The first of these foctors has a powerful influence on the melting point of a polymer.

- Legislative protection can have a direct effect on health.

- As a result of these technologies, televisual viewing changed radically.

- Age at weaning is younger in humans than chimpanzees and the interbirth interval is consequently $50 \%$ shorter (Kaplan et al., 2000: Hawkes and Paine. 2006).

cause $^{2} / \mathrm{ks:z} /$ noun $1[\mathrm{C}] \sim$ (of $\mathrm{sth}$ ) a person or thing that makes sth happen: The western Allies failed to understand the underlying causes of Russian resentment. \& Malthus saw population growth as the primary cause of poverty. 8 Tuberculosis was a major cause of death in Europe, and remains so in the developing world. $\mathbf{2}[\mathrm{U}]$ a reason for having particular feelings or behaving in a particular way: $\sim$ for sth The scientific evidence shows there is no cause for alarm. o without $\sim$ The symptoms can appear without apparent cause in some people. 3 [C] an organization or idea that people support or fight for: Orwell left for Spain to fight for the Republican cause. $\diamond$ Governments want to encourage charitable causes to be more active in seeking donations. o the $\sim$ of sth These global forces sometimes use their power to further the cause of democracy. [1]M] See COMMON

ADJECTIVE + CAUSE major, main, principal, primary, prime - underlying, root • possible, potential • likely, probable - immediate - common • proximate • sole • physical * unknown • contributory • ultimate - multiple In reality, the root causes of such problems often lie much deeper.

- VERB + CAUSE identify, determine + understand + exclude - treat Clearly, additional studies are required to identify the exact cause of this problem. | tackle, address . investigate, examine The Japanese economy grew very suddenly, prompting many countries to examine the causes of Japan's success. | further, advance - champion, espouse, support • promote Orwell's '1984' described how new technologies would advance the cause of totalitarianism.

caut tion ${ }^{2} /$ 'ko: $\mathrm{n} /$ noun [U] 1 care that you take in order to avoid mistakes or danger: Caution must be exercise when attempting to transfer sales methods from one culture to another. $\diamond$ with $\sim$ These drugs should be used with caution in patients at risk of developing diabetes. 2 a warning or a piece of advice about a possible danger or risk: a note/word of Some have sounded a note of caul. tion in connection with the practical application of this technique.

cau tion ${ }^{2} / \mathrm{ks}:[\mathrm{n} /$ verb $[1, T]$ to warn sb about the possible dangers or problems of sth: $\sim(\mathbf{s b})$ against sth Other environmentalists caution against abandoning Enlightenment

Fig. 3. Sample page from OLDAE 


\subsection{Meaning: the senses of headwords}

Inclusion of a given headword in both OLDAE and OALD8 does not mean that the same senses will be described, or that the same senses will be presented in the same order. In order to get an idea of what sort of differences there might be in this respect, I carried out a detailed comparison of 100 consecutive entries in OLDAE and their counterparts in the more general dictionary. The entries run from legal to limited liability in OLDAE, though two of the OLDAE headwords are not present in OALD8 (life course and life table). The following are the main points to emerge from this comparison.

1) For just over 40 entries there is only one sense (the same sense) in both dictionaries.

2) In a further 20 entries, with more than one sense, there are close parallels between the two dictionaries as regards both senses included and sequencing.

3) In 24 cases, one or more of the senses in OALD8 is not covered in OLDAE. Conversely, in seven cases there is one or more additional sense in OLDAE; to the latter can be added a further five OLDAE entries which do not have direct meaning counterparts in OALD8, since they are only present as undefined derived words. There are also a few entries in which each of the two dictionaries has one or more sense not listed in the other.

4) In a small number of cases, the ordering of senses is different.

Two examples of differing sense treatment are: (i) the verb liberate, which has one additional sense in OLDAE, that of 'to release gas, energy, etc. as a result of a chemical reaction or physical process'; and (ii) the noun lift, which has five senses in OALD8 but only two in OLDAE; furthermore, the first meaning of lift in OALD8 is that of 'elevator', while the first sense in OLDAE is that of 'upward pressure of air on an aircraft, a bird or an insect when flying'. Two further examples, from the headwords in Fig. 3, are the nouns caution and causality. The former has an additional sense in OALD8 (labelled $B r E$ ), that of 'a warning that is given by the police ...'. The word causality, by contrast, has the same two senses in both dictionaries, but in OLDAE they are formally divided while in OALD8 they are not (nor do they have example sentences).

\subsection{Defining, explaining, exemplifying}

The starting point for most of the definitions in OLDAE were the definitions in OALD8 (see Lea 2014: 185). Comparison of the definitions for comparable senses of the 100 headwords in the section legal to limited liability suggests that definitions are, in fact, very similar or identical in the two dictionaries. Presumably there will be some slight differences dependent on the fact that OLDAE's basic defining vocabulary is smaller than that of OALD8 (2,300 words as opposed to 3000).

A further aspect of the presentation of meaning in OLDAE is the fact that in some 'HELP' notes there is information about subject-specific uses of a headword or phrase. For example, at the entry for causation (see Fig. 3), there is an explanation of the use, in a legal context, of the phrase chain of causation. Another example involves the entry for analogous. There is one general sense of this headword, but in the HELP section of the entry we read that, 'In biology, analogous is used to describe two things that perform similar functions but have different evolutionary origins, such as the wings of insects and birds'. A third example relates to the verb diffract. In this case the HELP note is slightly different in nature, since it gives the reader factual knowledge as well as linguistic. The definition reads, 'to make light or other waves bend or spread out when they pass through a narrow opening or across an edge'; the HELP note adds the information that, 'In light, this process 
causes the light to break into a series of dark and light bands or into the different colours of the SPECTRUM'.

I turn now to example sentences. The first thing to point out is that all meanings in OLDAE are accompanied by at least one example of usage, whereas this is not the case for OALD8. This applies not only to headwords, but also to derived words and lexicalized phrases. For example, hybridization is a derived word in both OALD8 and OLDAE, and while there is no example in the former, in the latter we find 'Mendel was chiefly concerned with the hybridization of species as an alternative to evolution'. It is also to be noted that all contextualized examples in OLDAE are full, sentence-level items (or else involve more than one sentence when the meaning of the headword requires it), whereas this is not always the case for OALD8. For example, in OLDAE there are three sentence-level examples for the word agglomeration (e.g. 'The larger the area became, the more the agglomeration of firms made it attractive to others as a business site'), whereas in OALD there is just one, phrase-level, example ('an ugly agglomeration of buildings').

The fact that more space is devoted to examples in OLDAE than in OALD8, proportionally speaking, is a reflection of its primary concern, that of helping students engaged in written production tasks; also of relevance, no doubt, is the simple fact that the print version of the academic dictionary has fewer space constraints than OALD.

Naturally, since examples in the two dictionaries are based on typologically different corpora, the examples of usage are, in many cases, of a different nature. The following are examples in relation to two words, lid and let, neither of which have a particularly academic or technical feel to them: lid OALD8 a dustbin lid $\diamond I$ can't get the lid off this jar; OLDAE The bottle lids should finally be securely sealed and the contents gently mixed; let OALD8 Let them splash around in the pool for a while. $\checkmark$ Don't let her upset you; OLDAE They maximized productivity by letting a robot transport the finished parts from machine to machine. $\diamond$ Pores in the cell membrane let the potassium ions pass but block the passage of sodium ions.

With regard to 'authenticity', some examples in the OLDAE have been taken directly from the corpus, but many have been edited in some way. The reasons for this are explained in Lea 2014 (p. 188), and relate to such things as the level of the language (in relation to the dictionary user's knowledge), the length of sentences, and 'obscure and distracting detail'. Lea also points out that the students using the dictionary are not expected immediately to be able to write the same sort of language as is found in many of the corpus texts: "what they need to acquire is a style that approaches more closely an appropriate academic style, whilst still being accessible from the level they are currently at.' (ibid., p. 188).

A final point I will make in this section is that, at the time of dictionary compilation, a number of subject advisers were available to help with, among other things, the wording of definitions and the choice and wording of example sentences. A list of subjects (and advisers) can be found in the 'acknowledgements' section of the dictionary (p. iv).

\subsection{Usage labels}

In this section I comment on the various 'labels' which form part of lexical description in OLDAE, and compare them with the same labels in OALD8. Firstly, OALD8 has many more 'regional' labels than OLDAE (15 as against 3). The small number in OLDAE is presumably related to the nature of the corpus, and, more generally, to the standardization of international academic publications. The three labels in OLDAE are: British English, North American English, and English

from the United States. The distinction between the latter two mainly involves spelling, and relates to the fact that some 'British' spellings are quite normal in Canada but not in the US (personal communication from the editor). 
With regard to 'subject' labels, a total of 23 are used in OLDAE, and are listed on the inside cover of the dictionary. Different labels are sometimes found within the same entry. For example, the word matrix has five senses in OLDAE, and for three of these, different subject labels are used (MATHEMATICS, EARTH SCIENCE, BIOLOGY). The non-subject-specific label technical is also sometimes used, where there are a number of disciplines involved (see, for example, cathode in Fig. 3). In recent editions of OALD, there are more than 60 subject labels (communication from the publishers).

There are two main differences between OALD8 and OLDAE as regards style labels. Firstly, certain labels are not found in OLDAE, because of the nature of the texts; these are humorous, ironic, slang, and taboo. Secondly, the terms 'formal' and 'informal' are used differently in the two dictionaries. On the inside cover of OLDAE we read that ' $[\mathrm{t}]$ he formal label is used only for those words that are formal even by the standards of academic writing'. Thus, for example, the words legislative, legislator, and legislature are all labelled as 'formal' in OALD8, but in OLDAE they are not. By contrast, an example of a word labelled as 'formal' in both dictionaries is the abovementioned (4.2) agglomeration. With regard to informality, the dictionary informs us (inside cover) that there are very few items judged to be 'informal', but also that there are 'a number of rather informal expressions, such as cry out for sth and put your finger on sth, which may be used in more informal types of academic writing'. An example of single-word usage judged to be 'rather informal' is the noun giant, as in 'They were unable to compete with the global media giants'.

\subsection{Phraseology}

Fully lexicalized phrases are usually presented in OLDAE in the same way as they are in OALD8. That is, they are either headwords themselves, or they are in a section of 'phrasal verbs', or they are in a separate section of 'idioms' (a label encompassing any type of lexicalized phrase other than phrasal verbs).

The presentation of lexical collocation, by contrast, is different. Notably, a considerable number of entries in OLDAE include separate sets of collocations (690 is the number indicated on the back cover). In these sets, the words which act as starting points for collocational phrases (i.e. the headwords) are nouns, verbs, adjectives or adverbs. The resulting phrases either involve just openclass items, for example 'ADJECTIVE + cause' (as in 'likely cause' - see Fig. 3), or involve the presence of other words, especially prepositions, for example 'VERB + with age' (as in 'decline with age'). Most collocates are grouped according to grammatical structure, and within each group, collocates of similar meaning are placed together. The grammatical description of collocation can be quite precise. An example is the treatment of 'verb + adverb' combinations, which are presented either as 'ADVERB + VERB' or as 'VERB + ADVERB', if there is a typical order, or otherwise as 'ADVERB + VERB/VERB + ADVERB'. 11

In the print dictionary, collocation sets are placed at the end of the relevant entry, which means that there is no direct connection between collocates and any eventual subsenses of a headword (though the semantic grouping of collocates may help the dictionary user in this respect). On the CD-ROM, collocates are located both as a complete set at the end of entries and as a partial set after each subsense (see 5.3).

In addition to these collocation sets, there are also collocations indicated in the main body of entries. These are followed by example sentences, and the collocation itself is highlighted before (not within) the example. Two examples can be seen at caution n. (Fig. 3): a note/word of $\sim$ Some have sounded a note of caution in connection with the practical application of this technique; with $\sim$ These drugs should be used with caution in patients at risk of developing diabetes. 
Phrases, either lexicalized or collocational, also appear in some HELP notes. The phrase chain of causation was mentioned in 4.2. Other examples are distributed system and positive discrimination explained, respectively, at the entries for distributed and discrimination.

\subsection{Sets of items: connecting entries and meanings}

As is the case with other learners' dictionaries, in OLDAE there are various types of connection made between entries. Some are simple cross-references to lexical items of related meaning, while others involve bringing a number of items together in 'boxes' at specific entries. I will briefly discuss two of the latter type in OLDAE, entitled respectively 'Thesaurus' and 'Language Bank' (also found in OALD8, where the former is called 'Synonyms'). There are about forty of each, and the items concerned are listed in the introductory pages of OLDAE (pp. xi-xii).

In the thesaurus boxes, small numbers of similar lexical items are compared, through explanation, collocational patterning, and examples of usage. Grammatically, they are verbs, nouns or adjectives, and, from the point of view of meaning, they are almost all fairly general in nature. Examples of such thesaural groups are 'reject, deny, contradict, refute', 'result, outcome, finding, consequence', and 'essential, crucial, critical, vital'.

The Language Banks focus on specific ways of communicating or on general meanings which are important in academic writing. A list of the various 'topics' can be seen on p. xii. An example can be seen in Fig. 3, entitled 'Cause and effect'. Further examples are: 'Organizing your writing', 'Defining language', 'Comparing and contrasting', 'Describing statistics', and 'Emphatic language'. The majority of items within each set are exemplified with full sentences, as can be seen for 'Cause and effect'.

\section{The CD-ROM: further lexical resources and opportunities}

In this section I mention, above all, some of the ways in which the CD-ROM differs from the print dictionary with regard to its lexical resources.

To begin with, I should explain that the CD-ROM includes, in a sense, two different A-Z dictionaries. One is the digital equivalent of the print dictionary, with the slight difference that it includes more than 500 additional entries - this is data for which there was insufficient room in the print dictionary. The other is what is termed the 'Mini Dictionary', which is designed to help especially with comprehension. This is similar to the 'Genie' on the CD-ROM versions of recent editions of OALD. Figure 4 is a screenshot of the main 'dictionary' view, and at the bottom can be seen the button to switch to the Mini Dictionary, which I now describe in more detail. 


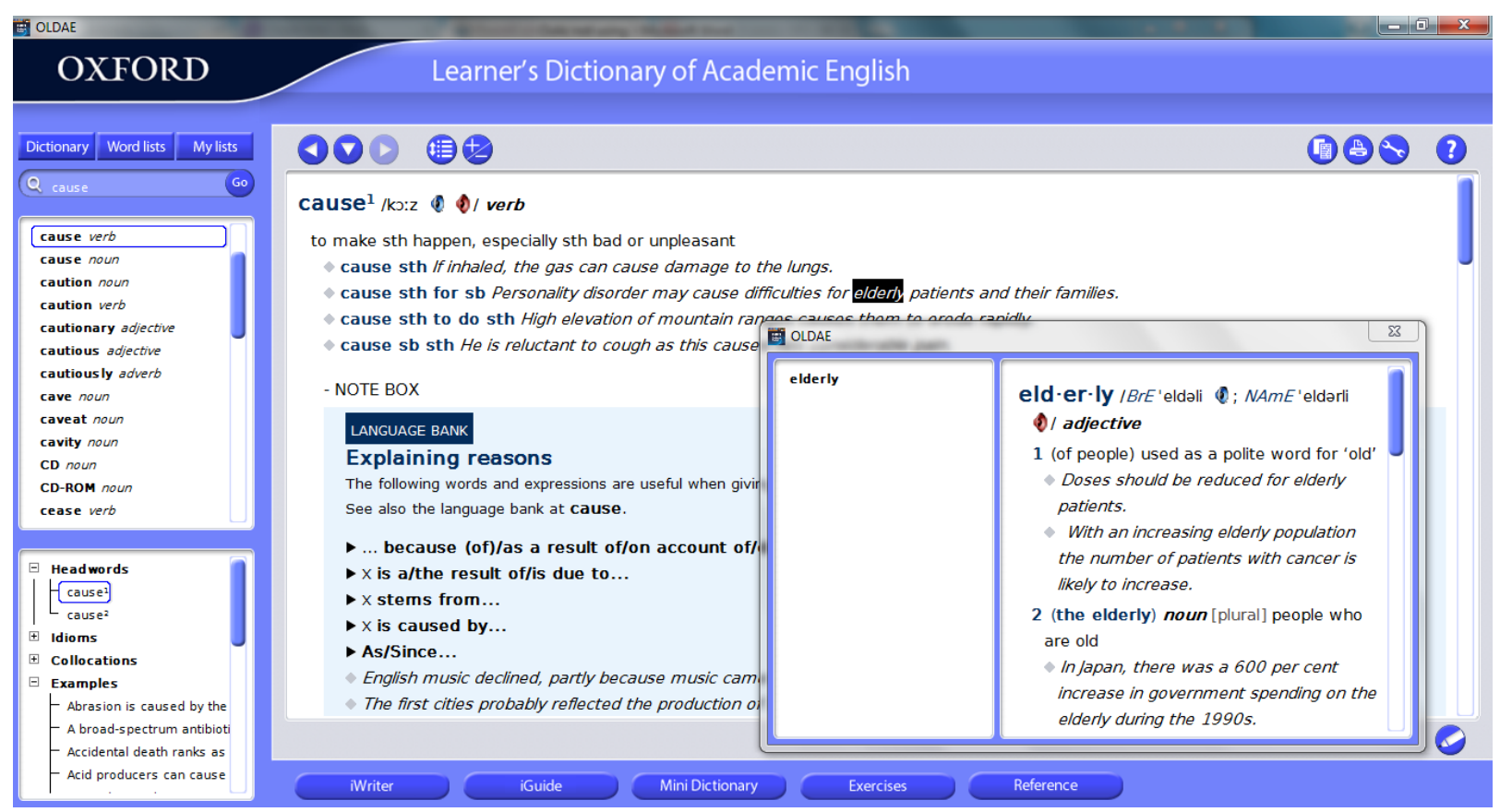

Fig. 4. Screenshot from the CD-ROM, including an entry from the Mini Dictionary

\subsection{The Mini Dictionary}

This dictionary resource consists of the entries in OLDAE itself, plus the definitions (just the definitions) for all those words which do not appear in OLDAE as headwords but are explained in OALD8 (in the latter case, the definitions are those used in OALD8). This 'dictionary' is 'mini' in the sense that it opens in a small window, and also in the sense that its intended purpose is just that of helping with comprehension. In terms of available data, however, it is far from 'mini', and for this reason I will distinguish between the 'two dictionaries' by referring to them by different forms of the same name: OLDAE and $0 \lambda \delta \alpha \varepsilon$. (The use of Greek characters can be seen as an allusion to the fact that the user is looking up the meanings of foreign words, rather than finding out how to use lexical items that he or she is already familiar with.)

$\mathrm{o} \lambda \delta \alpha \varepsilon$ can be consulted while using OLDAE itself, or while using certain other programs. When using the main dictionary, $\lambda \delta \alpha \varepsilon$isusefulespeciallyforcheckingthemeaningofwordsin definitions and example sentences. Double-clicking on a word will open o $\lambda \delta \alpha \varepsilon$ in a small window, on top of the main dictionary window (see elderly in Fig. 4). If there is more than one entry for the word form in question, $0 \lambda \delta \alpha \varepsilon$ will automatically open at the first one listed; if that is not the correct one, the user clicks on another item in the left-hand menu.

Turning to the use of $\mathrm{o} \lambda \delta \alpha \varepsilon$ outside the main dictionary, in the Help section of the CD-ROM we are informed that it works with a number of programs, either by hovering over a specific word with the cursor (in the case of certain programs), or else by double-clicking. Having tested this facility, my findings were that it worked very well with MS Word files, and also with Internet Explorer (though only if the zoom facility is set to 100\%). In other cases, it would not work at all. I am informed by the publishers that the problem lies with the speed of technological change: when a $\mathrm{CD}-\mathrm{ROM}$ has been designed to interact with certain other programs and browsers, there is no guarantee that it will continue to work well once these have been updated, in which case the CDROM developers will have to find a way of putting their own product back on track.

\subsection{The CD-ROM: search terms and results}


Initial searches on the CD-ROM are for individual words or strings of words, and will be successful if the search term is a headword or derived word in the dictionary, or a relative inflected form. If the search term is not recognized, a number of 'similar entries' will be suggested. For example, the first suggestions for 'searsh' and 'trem' are, respectively, 'search' and 'term'. If the search term is not in OLDAE but is in OALD8 (and therefore in $0 \lambda \delta \alpha \varepsilon$ ), then the reader will be informed of this fact.

The words 'searsh' and 'trem' are hypothesized 'typos'; however, far more important is the ability of a dictionary to help find words that the user does not know how to spell. Actually, when the initial letters are correct, the intended word may show up anyway in the aphabetical list of headwords in the top left-hand corner of the screen, sometimes before one has finished typing the search word. Whether this happens will obviously depend on how many other words begin with the same letters. Examples of (imagined) wrong spellings for which correct headwords may be found in this way are: benine, campain, easyly, hierarky, hygene, imparshal, intreeging, lable, manouver, manslauter, medievil, monark, morgage, moteef, mussle (= muscle), naeve, negligable, seperate, tempature. Searches were also made for a number of misspelt words for which the correct form did not show up in this way, and for which, therefore, the 'similar entries' window became more important. 23 word forms were looked for in all, and in 16 cases the correct headword was suggested. These are: bipass, carisma, garantee, hibrid, hipothesis, iminent, inaffective, intresting, leethal, leasure, liesure, liric, mistery, mithical, nieghbour, rythm, sitizen. The six word forms which did not return the correct solution are: asma (= asthma), garanty, higene, karisma, mistry, noosance.

A successful search leads both to an entry, and to an expandable menu from which other entries can be directly accessed (see Fig. 4). Notably, the user will be able to gain direct access to: (i) phrasal headwords of which the search term forms a part; (ii) 'idioms' and phrasal verbs of which it forms a part; (iii) collocates of the search term, when they appear in collocation sets at other entries; (iv) all example sentences in OLDAE in which the search term occurs. It is to be noted, however, that the lists of items suggested by the search term are not automatically differentiated if the search term belongs to more than one part-of-speech category, nor is it possible to differentiate them afterwards. Thus, for example, when one has retrieved the entry for the verb cause (see Fig. 4), the various items in the bottom left window could refer to either the verb or the noun. In the case of collocations and examples, in particular, this means that quite a lot of the retrieved items will be irrelevant to one's search. The situation just described also applies to adverbs which have a corresponding adjective headword in the dictionary (though not vice versa). Thus, for example, a search for effectively will return information about effective as well.

Although lists of collocates and example sentences are in some cases quite long, scrolling through the items in the menu is simple, and each item selected is displayed and highlighted in the main window in the dictionary entry to which it belongs. In the case of example sentences, the whole sentence is highlighted. For collocations, the collocate itself is highlighted wherever collocates have been separated into different lists (according to the subsenses of the headword); where there has been no need for a division into subsenses, the whole collocations set (collocates and examples) are highlighted.

\subsection{Lexical entries on the CD-ROM}

In this section I mention some of the ways in which the CD-ROM provides a more user-friendly interface to lexical entries than that which is offered by the print dictionary.

Firstly, as is now normal practice with most digital dictionaries, the user may choose whether or not to see certain information types on the screen, either at a particular moment or in terms of default settings. Secondly, the $\sim$ symbol is not used to represent the headword; thus, for example, the previsouly cited collocation a note/word of $\sim$ appears as a note/word of caution. Thirdly, and 
with regard to collocation sets (see 4.4), where there is more than one sub-sense of a headword, the relevant collocates are viewable at the end of each sub-sense (while all collocates can still be seen together at the end of the whole entry). Fourthly, all 'sets' of items (see 4.5) are available directly at all the relevant entries. By 'directly' available, I mean that it is not neceessary to click on an item and be taken to another entry; rather, the whole set of items is viewable at different entries. For example, in the screen shot in Fig. 4 we can see part of a Language Bank entitled 'Explaining reasons', but in the print dictionary this appears only at the entry because (to which it is crossreferenced from other entries).

Still with 'sets' of items, in addition to the sets provided by the dictionary, on the CD-ROM the user can draw up his or her own personalized lists of headwords. This is done quite simply by clicking on a specific symbol while at a particular entry. In this way, lists of items which have something in common can be created, saved with an appropriate name, and be available for future editing or consultation.

Lastly, the user can add personalized notes to individual entries. These are automatically stored as part of the dictionary entry for as long as one wishes, and can be displayed or hidden from view.

\subsection{Improving lexical knowledge through exercises}

The CD-ROM also contains exercises aimed at improving lexical knowledge, especially as regards word meaning, lexical collocation, and dependent prepositions. All questions in all exercises have as their starting point words from the sublists of the AWL, and all words in the exercises can be looked up in the dictionary by double-clicking.

There are five exercise types, which may be summarized as follows: (i) Match the words and the definitions; (ii) Choose the word or phrase that best describes the word in bold, e.g. Renewable energy looks more economical when the pollution abatement costs of nuclear energy are factored in [subtracted / included / multiplied]; (iii) Collocation: choose the most appropriate word to complete the sentence, e.g. All applications must be examined by the relevant regulatory [persons / bodies / forms / institutions]; (iv) Choose the correct preposition to complete the sentence, e.g. The account given by this witness seems to be inconsistent [with / to / from] the forensic evidence; (v) Choose the correct word to complete the sentence, e.g. Her lecture will discuss the main [methods / contexts / concepts / definitions] behind the theory of biological diversity.

\subsection{Word lists}

The CD-ROM also contains six 'word lists', and by clicking on any word in a list, the user can go directly to the corresponding entry in the dictionary. One list consists of the dictionary's defining vocabulary (2,300 words). Another is made up of all those words in the AWL which appear in OLDAE as headwords. The remaining four lists are related to the broad thematic areas of Humanities, Life Sciences, Physical Sciences, and Social Sciences; there are approximately 200 to 300 words in each list, and to exemplify the types of word included, the following are the words in each list which begin with the letter $f$ :

HUMANITIES: faith, false, famous, female (adj), film (n), film (v), formal, foundation, freedom, future (n).

LIFE SCIENCE: feedback, feeding, female (adj), female (n), fitness, flow (n), follow-up, formation, fragment, frequency, functioning (n). 
PHYSICAL SCIENCE: feedback, film (n), flow (n), flow (v), fluid (n), flux, formation, fraction, frame $(n)$, frequency, fuel $(n)$.

SOCIAL SCIENCE: facility, female (adj), feminist (adj), firm (n), fix (v), flow (n), form (v), formal, formation, freedom.

\section{Lexical entries: Guiding the dictionary user}

Guidance on how to use the dictionary is available in the print dictionary, on the CD-ROM, and on the publisher's website. In the print dictionary there is the standard introduction to the different data types in lexical entries, and explanations of abbreviations, symbols and labels used in the dictionary. The CD-ROM includes a section termed iGuide, in which guidance becomes more interactive through the use of clicking and drag-and-drop activities. These are well designed exercises which aim to introduce the reader to two types of information: (i) the meaning of abbreviations and symbols, and (ii) the content and structure of lexical entries. As part of the exercises, readers must also be, or become, familiar with basic linguistic and dictionary terminology (e.g. synonym, primary stress, headword, cross-reference).

On the publisher's website there are additional 'Teaching Resources'. These consist of downloadable Worksheets and Lesson plans. The photocopiable worksheets, together with detailed teacher's notes, cover the following areas of dictionary usage (using the titles on the website): Understanding the meaning; Collocations; Word grammar and dependent prepositions; Finding the right word (in relation to different parts of speech and derivatives); Making use of example sentences; Word families; The usage notes (covering the types of data found under the headings THESAURUS, WHICH WORD?, and LANGUAGE BANK); Making use of the Help notes. There are also two Lesson Plans, one in relation to dictionary entries and the other regarding the iWriter (see Section 7).

\section{OLDAE: Beyond lexical data}

Recent editions of learners' dictionaries contain a considerable amount of data which is irrelevant to the typical definition of the word 'dictionary'. Dictionaries are about 'words and phrases', but MLDs now typically include sections devoted to other aspects of language description and language learning. OLDAE is no exception, with a section on writing, and a more general 'reference section'. These form part of both the print dictionary and the CD-ROM.

The 47-page 'reference section' deals mostly with recurrent language features (grammar, phraseological types, punctuation) and some more specific data types (numbers, geographical names, affixes, abbreviations). In most cases, the information is quite closely linked to the dictionary proper, either through reproductions of parts of entries exemplifying what is being discussed, or through the use of corpus-based examples.

Turning now to writing, OLDAE contains a section termed the Academic iWriter on the CDROM, and Academic Writing Tutor in the print dictionary. This is similar in nature to the writing sections in OALD8 and OALD9, though more specific to academic writing. It includes various 'models' of writing, and covers a range of disciplines. Models include specific text types (e.g. compare-and-contrast essay), specific parts of texts (e.g. social science abstract), data types within texts (e.g. literature review), and ways of presenting data (e.g. bar charts). Almost all of the models used are either published texts or were written by British university students (see the References section of the iWriter). Specific parts of the models are highlighted and explained, and additional 
useful language is pointed out. On the CD-ROM, there are two options available to the user: that of viewing 'models' of writing and that of writing one's own text on the basis of these models. In the latter case, the writer works with the aid of explanations and structured frameworks.

\section{Conclusions}

I will conclude this article by first giving an overall evaluation of OLDAE, and thereafter making a few general points about the evolving field of monolingual pedagogical lexicography.

\subsection{OLDAE: summary and evaluation}

My overall evaluation of OLDAE is a very positive one. It is a well-thought-out dictionary which offers new resources to a specific user group. The principal aim of the dictionary is to help students with their written English, and it provides a considerable amount of data which should prove useful in this regard. This data takes the form, primarily, of the A-Z dictionary itself and the specific section on writing. The latter, the iWriter, appears to be very well constructed, and, in addition, it provides an opportunity to see examples of university student writing.

With regard to the dictionary proper, the overall approach taken by OLDAE is that of providing detailed information about how to use lexical items with which the user is already familiar, especially through the presentation of example sentences, typical collocations, and complementation patterns. OLDAE may, from this perspective, be contrasted with reference works in which the point of departure is largely 'meaning' (e.g. the Longman Language Activator). Meaning (and function) are also starting points in OLDAE but mainly as regards important and recurrent textual elements.

Examples of usage in OLDAE are intended, above all, to be pedagogically useful, as has been seen above (4.2). I very much concur with this approach. Corpus analysis is essential for lexical description but this does not mean that dictionary examples must, of necessity, correspond exactly to strings of words which occur in the corpus. And when examples of usage are taken directly from the corpus, there is the risk that they might, indeed, become little more than 'strings of words', since there is no contextualization at all. The examples in OLDAE, although they have no context, appear to be complete textual units of meaning which are communicating something to someone. At the same time, they do not come across as being contrived in any way.

With regard to the number of examples, it is very positive that all senses of all headwords and derived words are exemplified in OLDAE. However, there is one aspect of lexical description which would benefit from more examples: this is lexical collocation. In the many collocation sets, only a small proportion of the collocational phrases are exemplified. This is not a problem in itself: often it should be fairly clear to the average student how phrases would typically be used. For example, at the entry for money only two out of the 20 phrases with the structure 'VERB + MONEY' are exemplified, but, at the same time, there would be little to gain by providing more examples. By contrast, there are other phrases in the same entry which would, in my opinion, benefit from examples of usage. These are the collocation 'cheap + money' and two 'NOUN + MONEY' phrases, 'purchase + money' and 'loan + money'. A further example, involving a verb, is the phrase 'drive + cycle', which is one of the phrases listed for the structure 'VERB + CYCLE'.

Although the teaching of writing is the main aim of the OLDAE, general lexical knowledge and awareness must also be mentioned in an appraisal of the dictionary. Many different aspects of the dictionary are useful from this point of view, among which, the AWL-based exercises, the availability of $\mathrm{o} \lambda \delta \alpha \varepsilon$ to look up unknown words, and the opportunity to add one's own notes to lexical entries. 
A final aspect I will comment on is visual presentation and access to data. Here, I have found little to fault in either the print dictionary or the CD-ROM. Visual presentation is very good in both. In the print dictionary I would mention, in particular, the very good use of colour to help with the description of textual elements discussed in the i-Writer, and on the CD-ROM I would single out the exercise on 'building a dictionary entry'. Some specific limitations of the CD-ROM were mentioned above (5.1 and 5.2), but apart from these, I found it a very user-friendly medium.

\subsection{The evolving contents and contexts of the MLD}

In this final section, I use OLDAE as a point of reference in order to comment on some of the ways in which the field of pedagogical lexicography is evolving. I do so via a list of more or less separate points.

(1) The Oxford Learner's Dictionary of Academic English is an example of how previous lexicographical methodologies can be used and adapted to produce a dictionary which caters for a more specific user group. Such initiatives are very much to be welcomed.

(2) The production of OLDAE also involved taking advantage of data used in another dictionary (the definitions in OALD8), which must be seen as the useful exploitation of digital resources.

(3) Most dictionaries aim to help with both production and comprehension tasks. However, in the digital age, it is now possible to achieve the two aims separately within the 'same dictionary'. An example of this is OLDAE, conceived of as a production dictionary, and the parallel resource I have referred to as $0 \lambda \delta \alpha \varepsilon$

(4) In the lexicographic subfield of 'learners' dictionaries', the noun dictionary now has more than one meaning (or 'use'). On the one hand, it corresponds to meaning 1a in the 3rd edition of the OED, which may be seen in the following endnote. ${ }^{12}$ On the other hand, dictionary is a word used in the title of reference works which include more data types than those indicated in the OED definition. As has been seen above, OLDAE includes, among other things, lexis-based languagelearning exercises, detailed explanations of how to write English texts in academic settings, and grammatical information of relevance to academic writing. Such information is not material thrown in to make the package look more attractive - it is very much a part of the 'dictionary' and is often linked directly to the lexical entries themselves.

(5) Although, in an ideal world, dictionary consultation should not create too many difficulties, the reality is probably different, especially as regards the underuse of dictionary resources. Some sort of guidance from within the dictionary is, therefore, a useful thing. OLDAE has very good interactive exercises on the CD-ROM, and OALD9 includes a video presentation of the dictionary.

In addition to having resources such as the ones just described, I think it would be useful to advertise them more. For example, in the case of a CD-ROM, as soon as one has finished installation, a pop-up window could appear, inviting the user to use a particular introductory activity.

(6) In relation to the previous point, it is also worth mentioning that the digital format of dictionaries now means that it is easier for 'learning about the dictionary' to be a group activity coordinated by a teacher, rather than just an individual activity. In a 1986 publication, Tom McArthur wrote, in regard to 'general works of reference', that: 'the attitude of educational systems is different towards them from the attitude to textbooks and course materials ... [T] hey are seldom mediated by teachers and hardly ever seen as needing mediation by teachers' (McArthur, 1986: 62). There is probably still a lot of truth in this, though at least the digital format of many dictionaries now makes it easier for that mediation to take place. 
(7) I have said above that my overall evaluation of OLDAE is a very positive one, but my opinions are only those of someone who has studied the dictionary, not someone who has used it. The most useful evaluation will come from students themselves, especially through well organized user studies.

\section{Notes}

${ }^{1}$ The specification 'widely available' is necessary since, as Lea reports (2014: 182), another EAP dictionary (online only) has been developed at the Centre for English Corpus Linguistics at the Université Catholique de Louvain; however, at the time of writing it is available only for use by students and staff at that particular university. The dictionary in question is the Louvain EAP Dictionary (LEAD). For details, see Granger and Paquot (2010a, 2010b) and Paquot (2012), as well as http://www.uclouvain.be/en-322619.html (accessed 12/05/2015).

${ }^{2}$ For reasons of space, in this article I do not discuss the app, which, in any case, contains just the main $\mathrm{A}-\mathrm{Z}$ part of the dictionary.

${ }^{3}$ IELTS stands for the International English Language Testing System; further information can be found via the organization's website, currently http://www.ielts.org (accessed 09/05/2015).

${ }^{4}$ Coxhead 2000 also appears in Basturkmen (ed.) 2015. The latter is a four-volume publication which brings together a total of 68 journal articles and book chapters of relevance to EAP, which were published between the years 1962 and 2014.

5 For further details of the Academic Keyword List, see also http://www.uclouvain.be/en372126.html (accessed 19/05/2015).

${ }^{6}$ For further details of the Academic Collocation List, see

http://pearsonpte.com/research/academic-collocation-list/ (accessed 19/05/2015).

${ }^{7}$ For more information regarding the Academic Vocabulary List, see: http://www.academicvocabulary.info/ (accessed 19/05/2015)

${ }^{8}$ On the publisher's website it states that '[m]ost of the words in the Academic Word List are included in MCD.':

http://www.macmillandictionaries.com/features/how-dictionaries-are-written/macmillancollocations-dictionary/ (accessed 01/04/2015).

${ }^{9}$ For some discussion regarding the notion of 'corpora of academic English', as well data on corpora which have been compiled, see Ackermann et al (2011), Krishnamurthy and Kosem (2007), Nesi (2008), Thompson and Nesi (2001), and, with reference to learner corpora in particular, Gilquin et al (2007).

${ }^{10}$ Aligning the lexical data in the AWL with OLDAE dictionary entries is by no means simple, since the former is exclusively based on word forms while the latter, in terms of headwords/derived words, (a) brings together different spellings of the 'same' word, (b) brings together grammatically inflected forms of the same lexical item, and (c) differentiates between different parts of speech of the same word form.

${ }^{11}$ OALD8 and OALD9 also include collocation sets, but they are fewer in number, and consist of semantically related sets of items located at one of the relevant entries.

12 'A book which explains or translates, usually in alphabetical order, the words of a language or languages (or of a particular category of vocabulary), giving for each word its typical spelling, an explanation of its meaning or meanings, and often other information, such as pronunciation, etymology, synonyms, equivalents in other languages, and illustrative examples.' (OED, online edition, accessed 23/05/2015). 


\section{References}

\section{A. Dictionaries}

Cambridge Business English Dictionary. 2011. Cambridge University Press.

Dictionary of Government and Politics. 1997 [1988]. Teddington: Peter Collin Publishing. (Since 2002 distributed through Bloomsbury Publishers).

Collins CoBUILD English Language Dictionary (editor in chief, J. Sinclair). 1987. London: Collins.

Longman Language Activator (editorial director, D. Summers). 1993. Longman.

Macmillan Collocations Dictionary for Learners of English (ed., M. Rundell). 2010. Oxford: Macmillan Publishers Ltd. (MCD)

Oxford Advanced Learner's Dictionary 8th edn. 2010. Oxford University Press. (OALD8)

Oxford Advanced Learner's Dictionary 9th edn. 2015. Oxford University Press. (OALD9)

Oxford English Dictionary, online edition. Oxford University Press. (OED)

Oxford Learner's Dictionary of Academic English (Chief editor, D. Lea). 2014. Oxford University Press. (OLDAE)

\section{B. Other References}

Ackermann, K. and Y. Chen. 2013. 'Developing the Academic Collocation List (ACL) - A Corpus-Driven and Expert-Judged Approach.' Journal of English for Academic Purposes 12: 235-247.

Ackermann K., de Jong, J., Kilgarriff, A. and D. Tugwell. 2011. 'The Pearson International Corpus of Academic English (PICAE)'. In Proceedings of the Corpus Linguistics Conference, University of Birmingham (20-22 July 2011). Available at (accessed 21/05/2015):

http://www.birmingham.ac.uk/documents/college-artslaw/corpus/conferencearchives/2011/Paper-47.pdf

Basturkmen, H. (ed.) 2015. English for Academic Purposes. Routledge: London.

Bernal, E. and J. DeCesaris (eds). 2008. Proceedings of the 13th Euralex International Conference (15-19 July 2008). Barcelona: Universitat Pompeu Fabra. http://www.euralex.org/proceedings-toc/euralex_2008/ (accessed 01/04/2015)

Bruce, I. 2011. Theory and Concepts of English for Academic Purposes. New York: Palgrave Macmillan.

Coxhead, A. 2000. 'A New Academic Word List.' TESOL Quarterly 34.2: 213-238.

Coxhead, A. 2011. 'The Academic Word List 10 Years On: Research and Teaching Implications'. TESOL Quarterly 45/2: 355-362.

Eldridge, J. 2008. 'A Reader Responds to K. Hyland and P. Tse's «Is there an "Academic Vocabulary”?».' TESOL Quarterly 42.1: 109-113.

Gardner, D. and M. Davies. 2014. 'A New Academic Vocabulary List.' Applied Linguistics 35.3: 305-327.

Gilquin, G., Granger, S. and M. Paquot. 2007. 'Learner Corpora: The Mssing Link in EAP Pedagogy'. Journal of English for Academic Purposes 6: 319-335.

Granger, S. and M. Paquot. 2010a. 'The Louvain EAP Dictionary'. In Proceedings of the XIV Euralex International Congress (Leeuwarden, The Netherlands, 6-10 July 2010), 321-326. 
Granger, S. and M. Paquot. 2010b. 'Customizing a General EAP Dictionary to Learner Needs'. In S. Granger and M. Paquot (eds), eLexicography in the 21st century: New Challenges, New Applications. Louvain la neuve: Presses universitaires de Louvain, 87-96.

Hollósy, B. 1990. 'On the Need for a Dictionary of Academic English'. In Magay T. and J. Zigáni (eds), BudaLEX '88 Proceedings: Papers from the 3rd International Euralex Conference (Budapest, 4-9 Sept 1988). Budapest: Akadémiai Kiadó, 535-542.

Hyland, K. and L. Hamp-Lyons. 2002. 'EAP: Issues and Directions'. Journal of English for Academic Purposes 1: 1-12.

Hyland, K and P. Tse. 2007. 'Is There an “Academic Vocabulary”?' TESOL Quarterly 41.2: 235253. (Also republished in Basturkmen 2015)

Jordan, R. R. 2002. 'The Growth of EAP in Britain'. Journal of English for Academic Purposes 1: 69-78.

Kosem, I. 2008. 'Dictionaries for University Students: A Real Deal or Merely a Marketing Ploy?' In Bernal and DeCesaris (eds), 1575-1584.

Krishnamurthy, R. and I. Kosem. 2007. 'Issues in Creating a Corpus for EAP Pedagogy and Research'. Journal of English for Academic Purposes 6: 356-373.

Lea, D. 2014. 'Making a Learner's Dictionary of Academic English'. In Abel, A., C. Vettori and N. Ralli (eds), Proceedings of the XVI EURALEX International Congress: The User in Focus (Bolzano, Italy, 15-19 July 2014). Bolzano/Bozen: Institute for Specialised Communication and Multilingualism, 181-189.

McArthur, T. 1986. Worlds of Reference. Cambridge University Press.

McCarthy, M. and F. O'Dell. 2008. Academic Vocabulary in Use. Cambridge University Press.

Nesi, H. 2002. 'An English Spoken Academic Wordlist'. In Braasch, A. and C. Povlsen (eds), Proceedings of The 10th Euralex International Congress (Copenhagen, Aug 13-17, 2002). Copenhagen: Center for Sprogteknologi, 351-357.

Nesi, H. 2008. 'Introducing BAWE: A New Lexicographical Resource'. In Bernal, E. and J. DeCesaris (eds),737-740.

Paquot, M. 2010. Academic Vocabulary in Learner Writing: From Extraction to Analysis. London and New York: Continuum.

Paquot, M. 2012. 'The LEAD Dictionary-cum-Writing aid: an Integrated Dictionary and Corpus Tool'. In Granger, S. and Paquot, M. (eds) Electronic lexicography. Oxford University Press, 163-185.

Sim, D. D. and B. Laufer-Dvorkin 1984. Vocabulary Development [Collins Study Skills in English]. London and Glasgow: Collins ELT.

Simpson-Vlach, R. and N. C. Ellis. 2010. 'An Academic Formulas List: New Methods in Phraseology Research'. Applied Linguistics 31.4: 487-512.

Thompson, P. and H. Nesi. 2001. 'The British Academic Spoken English (BASE) Corpus Project'. Language Teaching Research 5 (3) 263-26.

Xue, G. and I.S.P. Nation. 1984. 'A University Word List'. Language Learning and Communication 3.2: 215-229. 